\title{
THE PLACE OF FOLIANDRIN WITHIN THE GROUP OF CARDIAC GLUCOSIDES
}

\author{
BY \\ L. E. SCHINDEL AND K. BRAUN \\ From the Medical Department of the Hadassah University Hospital, Jerusalem \\ Received January 21, 1944
}

The need for a home-grown cardiac glucoside has made itself felt in increasing measure during the last few years, and as a consequence a great number of plants of this country have been studied and tested for their possible content of cardiac principles. Popular medicine and the oldest botanical, i.e. biblical, literature helped to discover the way that promised the quickest success and eventually led to the pharmaceutical utilization of the leaves of the oleander bush (Nerium oleander).

The wild Palestinean oleander bush belongs to the species of Apocynacere, containing in its leaves a glucoside which could be isolated in a pure crystalline form. The crystals are arranged in colourless tufts, the melting-point being $245^{\circ}$. The glucoside is optically active, rotating polarized light to the left.

Amorphous as well as crystalline substances had already been extracted from oleander leaves. Schmiedeberg (1883) was probably the first to isolate various principles from those leaves. He distinguished between neriin, nereantin, and oleandrin. Pharmacologically, he found that neriin and oleandrin exhibited a digitalis-like activity so that he called the former oleander-digitalein. French authors (Pieszcek, 1880; Leulier, 1889; and DubigadonDurieux, 1911) also reported isolation of cardiac principles from the bark of the Algerian variety of oleander.

Windaus and Westphall (1925) undertook the chemical analysis of these amorphous and crystalline substances. But it was not before Flury and Neumann's successful isolation of a pure crystalline product from oleander, in 1935, that the path was smoothed for the study of the chemical constitution. The results of these studies can be summarized as follows: oleandrin is optically active, rotating the light to the left, and upon hydrolization yields an aglycone, the oleandrigenin, which is identical with acetyl-gitoxigenin. Moreover, a sugarresidue, the "oleandrose," is split off, in which, however, none of the sugars so far known to play a part in digitalis chemistry could be identified (Shoppee, 1942).

The physical and chemical data reported by various authors for the sorts of oleandrin hitherto isolated show much divergency; this should not, however, surprise us if we consider that the habitat of the various oleander species as well as the technical methods used also show wide variations. Certain differences have even been established between the pure oleander glucoside manufactured in this country, the foliandrin, and that described by Flury (1935). Thus, for example, foliandrin has its melting-point at $245^{\circ}$ as compared with $249^{\circ}$ given by Flury. One cat-unit of foliandrin is equivalent to $0.324 \mathrm{mg}$. $/ \mathrm{kg}$., while for Flury's principle it is $0.25 \mathrm{mg} . / \mathrm{kg}$.

Clinical application also revealed differences between these two sorts of pure oleander glucosides. Thus a complete and lasting digitalis effect is attributed to Flury's principle. while the specific cardiac effect of foliandrin appears with surprising rapidity with no need 
for cumulation, particularly with reference to the auriculo-ventricular conduction. It acts, in addition, as a powerful stimulus to diuresis. Two electrocardiograms from a man, aged 56 , who suffered from heart failure, may serve as an illustration of the foliandrin effect in the human subject. Clinically, his heart had been found enlarged in all directions. At the time of examination, pulmonary infarction was, moreover, diagnosed. In the first there was auricular fibrillation at a rate of 190 a minute (Fig. 1, A). After he had been given foliandrin

A

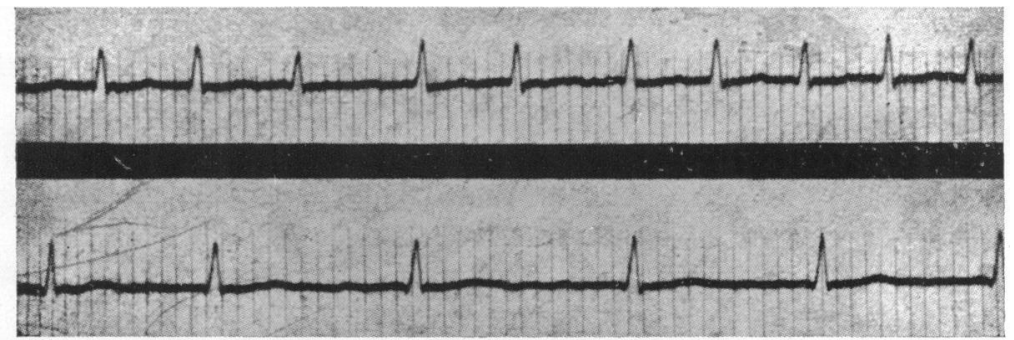

Fig. 1.-The effect of foliandrin on auricular fibrillation. (A) Before, (B) after a fairly full course by mouth.

for two days $(4 \times 50$ drops per day) - which, in fact, is very near to the tolerance dosefollowed by $4 \times 1$ foliandrin suppositories, the pulse rate dropped to 120 a minute on the third and to 90 a minute on the following day (Fig. 1, B).

Analysis of the clinical effect meets with a certain amount of difficulty. The time when the drug is given, the particular pathological stage, extra-medicinal factors influencing the treatment, etc., often play so vital a part that the effect of a certain principle must necessarily be different in every individual case. As clinical studies alone did not suffice, other methods had to be looked for to make it possible to assign the place to foliandrin within the group of cardiac glucosides. We tried, therefore, to get the necessary information from the reactions seen in the cardiogram of a cat after injection of one cat-unit of foliandrin. There is some diversity of opinion as to what should be deduced from the cardiographic changes occurring after administration of cardiac glucosides. The number of authors who consider the changes appearing after digitalis administration (lengthening of the P-R interval, inversion of the $T$ wave, etc.) a specific effect of the drug is probably just as large as the number of those who attach less importance to them (Weese, 1936; Cattell and Gold, 1941; Moe and Visscher, 1938; Walther, 1904; and Brams, 1929). With due allowance for divergencies arising from the different methods, the following may be accepted. Allowing for certain variations due to dosage, anæsthetic method, and the duration of the action of the drug, the shape of the cardiogram may well be considered as characteristic, as regards the decrease in height or inversion of the $\mathrm{T}$ wave, the bowl-type or angulated-type of depression of the R-S-T segment, etc. These changes do not, however, suffice nor do they show a sufficiently high degree of reliability to allow of definite conclusions as to the therapeutic or toxic dosage (Gold et al., 1931) of the glucoside or as to morphological changes of the heart muscle (Dearing et al., 1943). However, there are two characteristic features that are, indeed, able to give information on the quality of the cardiac glucoside in question, viz. the onset of sinus bradycardia and of ectopic beats, especially if the doses employed are those established as fatal for the particular experimental animal.

This is corroborated by two papers published quite recently. In the article published by Dearing, Barnes, and Essex (1943) the great number of variations of the electrocardiogram appearing upon administration of the various cardiac glucosides are set in relation to morphological changes of the heart muscle. Krueger and Unna (1942) followed up these changes over the whole period during which the glucoside effect took place, grouping them according to the nature of the glucoside as well as to the doses administered. They used for this purpose a recently devised "heart-rate recorder" which made it possible to trace the frequency and 
regularity of the heart beat on an ordinary lamp-black kymograph. They found two main differences between the effect of digitoxin (Merck) and ouabain (Merck): ouabain reduced the heart rate as early as after 15 per cent of the fatal dose, while with reference to digitoxin, reduction of the sinus rhythm occurred only after roughly 30 per cent had been injected. Similar data were established by Bauer and Reindell (1938) by Walther (1940) and by Robinson and Wilson (1918) with a different experimental method. Another difference between the effect recorded after digitoxin and ouabain was the appearance of " irregularity of heart beats." Krueger and Unna pointed out that with digitoxin, cardiac irregularity made its appearance after 76 per cent, and with ouabain after the administration of 58 per cent of the fatal dose. It should, however, be borne in mind that the anæsthetic method employed may be the cause of deviations of up to 2 per cent. The data so far published concerning the "cardiacirregularity dose" are 70 per cent (Planelles and Werner, 1923) and 68 per cent of the fatal dose (Bauer and Reindell, 1938).

The two characteristic features referred to above-reduced heart rate and the appearance of arrhythmia - can be objectively established, and if artificial stimuli, as strangulation or cooling, are eliminated, the changes are, in fact, only attributable to the glucoside administered. Objective recording of these changes is possible by cardiographic tracings. We, therefore, chose this method to ascertain the position of foliandrin within the group of cardiac glucosides. Since for foliandrin-provided that a certain experimental method is adhered to-the fatal dose has been established as $0.324 \mathrm{mg} . / \mathrm{kg}$. \pm S.E. of 0.019 which is equivalent to one cat-unit, it was a simple procedure to arrange for intravenous injections that would contain a quantity sufficient to produce systolic syncope in the experimental animal.

\section{METHODS AND RESUlts}

Cats weighing from 1.5 to $3.5 \mathrm{~kg}$. received intravenous injections into the femoral vein of one cat-unit of foliandrin respectively in urethan anæsthesia $(1.8 \mathrm{~g} . / \mathrm{kg}$.) and the development of the cardiac action was followed up in the electrocardiogram until death occurred. We always took the second lead (left foreleg-left hindleg). The required quantity of foliandrin, was prepared from a stock solution containing $40 \mathrm{mg}$. of foliandrin per 100 c.c. in 96 per cent alcohol. Normal saline was added to make the volume up to 10 c.c. for every injection The time during which the solution was injected was always the same, 5 minutes. After 15 . $25,50,75,90$, and 100 per cent of the fatal dose had been injected, a cardiogram was recorded and the further development followed up oscilloscopically. As soon as particular rhythmic changes made their appearance, tracings were again taken. Thus it was possible to record the entirety of the events taking place in the cat's heart from the beginning of the injection until its death. An illustration of this method, so far tried in 6 cats, is shown in Fig. 2. We only accepted the onset of slowing of the heart-rate and irregularity of the beats as an indicator of the foliandrin effect. On purpose we do not enter into detail as to the changes of the $T$ wave or of certain intervals.

The reactions taking place in the cardiac muscle and auriculo-ventricular conduction system, if syncope is produced by foliandrin, are shown in the 12 cardiograms of Fig. 2, which were taken from a continuous $15 \mathrm{~m}$. long film.

The results of the above studies show that (1) reduction of the heart rate occurs as a result of intravenous injection of foliandrin which sets in after 15 per cent of the fatal dose $(=$ one cat-unit) has been introduced, and (2) the first signs of irregularity of the heart beat appear after 50 per cent of the fatal dose (=cat-unit) has been given.

The following table gives the data for digitalis, ouabain, and foliandrin with reference to the above mentioned signs.*

* Experiments conducted by us with digitoxin "Roche" and strophantin (Burroughs Wellcome) have, essentially, yielded the same results as those published, although the number of data at our disposal is too small to allow of definite conclusions. 


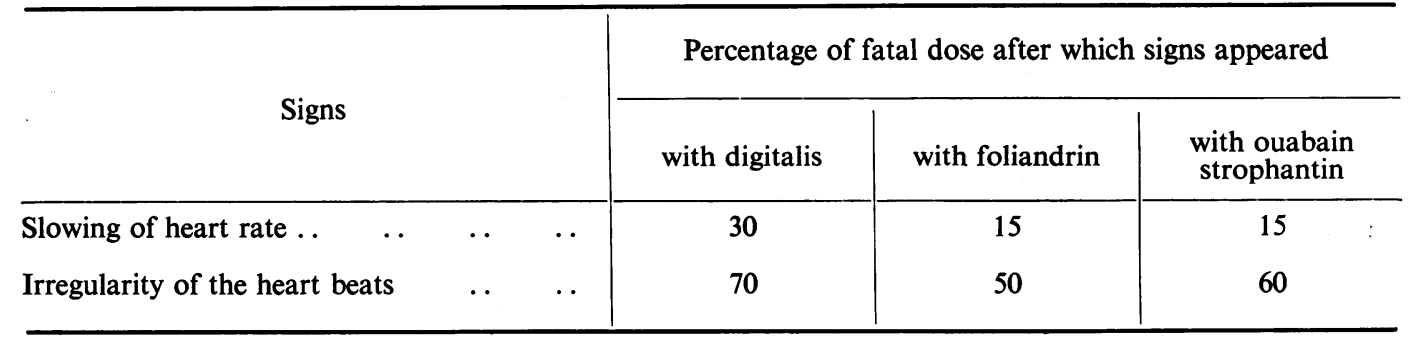
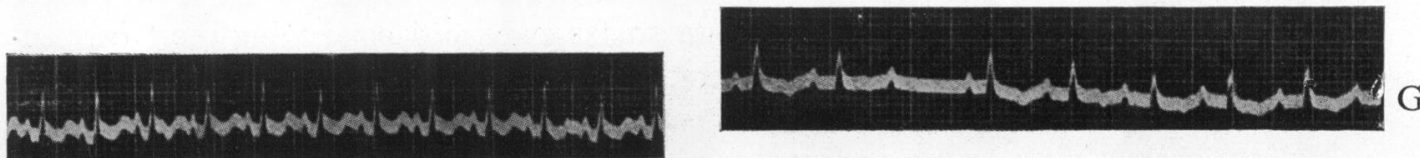

B
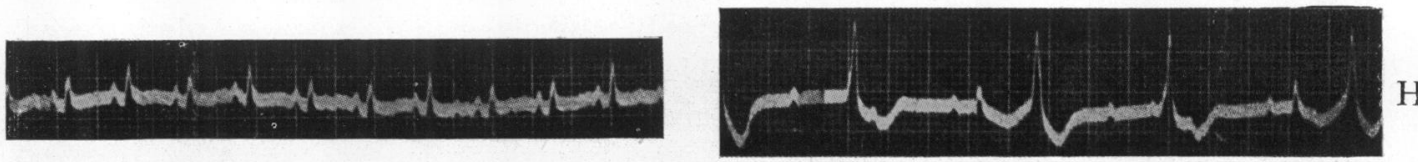

C
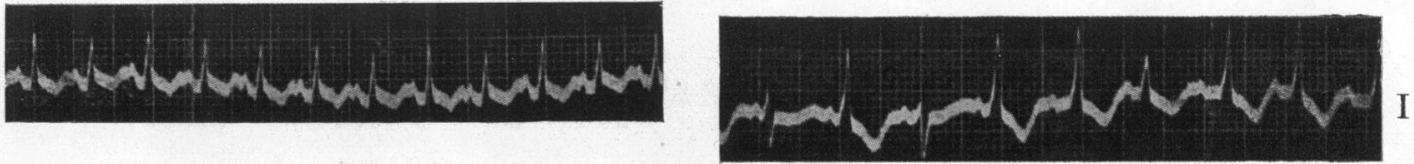

D
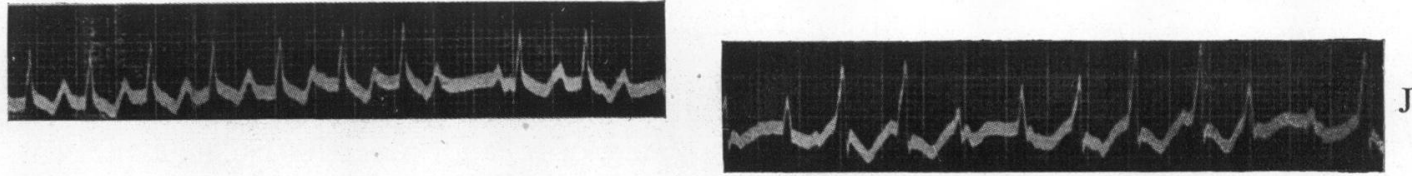

E
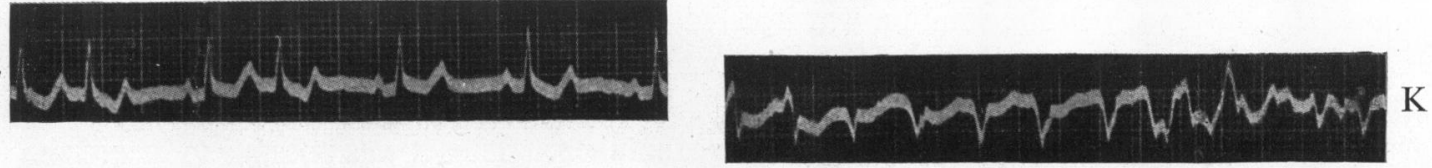

F
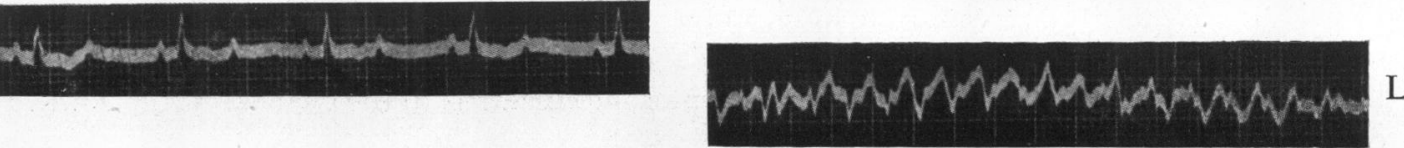

Fig. 2.-Twelve cardiograms taken on a continuous long film from a normal cat (A) Before the administration of foliandrin. (B)-(F) After the administration of various percentages of the fatal dose (=1 cat-unit). (B) After 15 per cent with some reduction of rate. (C) After 25 per cent. (D) After 50 per cent.

(E) After 75 per cent, showing the first signs of irregularity. (F) After 90 per cent. (G)-(L) Terminal stages after 100 per cent fatal dose (=1 cat-unit).

Comparing the results obtained with digitalis, ouabain, and foliandrin, we may conclude that the oleander glucoside foliandrin is very closely related to ouabain, in any event belonging to the category of the strophantin glucosides rather than to that of digitalis.

These results gain particular importance in a clinical respect. Strophantin is so rapidly and completely broken down in the intestinal tract that practically no cardiac effect can be expected after oral administration, while for foliandrin clinical experience has shown that the full cardiac, effect may be produced by oral administration, and that the specific effect occurs 
very rapidly. It should be included in the strophantin rather than in the digitalis group, and should, therefore, be considered a " strophantinoid." As far as we know, therefore, foliandrin is the first glucoside of this group to develop its full cardiac activity in the peroral route.

The drug has so far been tested on human patients in the Hadassah University Hospital, Jerusalem, the Hadassah Municipal Hospital, Tel-Aviv, and the Government Hospital, Haifa and Jerusalem. Results will be published elsewhere.

\section{SUMMARY}

The pure glucoside foliandrin isolated from the Palestinean oleander bush (Nerium oleander) distinguishes itself very definitely from principles so far isolated from various oleander species. Apart from other chemical as well as physical characteristics, it could be shown by means of continuous electrocardiographic tracings from a cat's heart, that upon intravenous administration its action is identical with that of the principles belonging to the group of strophantin (ouabain) glucosides and the drug should therefore be considered a "strophantinoid." In contradistinction to strophantin, it displays its full cardiac activity upon peroral administration.

\section{REFERENCES}

Barnes, A. R., and Essex, H. E. (1943). Amer. Heart J., 71, 114.

Bauer, H., and Reindell, H. (1938). Arch. exp. Path. and Pharm., 190, 461.

Brams, W. A., (1929). Arch. intern. Med., 43, 676.

Cattell, McK., and Gold, H. (1941). J. Pharm. Exp. Therap., 71, 114.

Dearing, W. A., and co-workers (1943). Amer. Heart. J., 25, 665.

Dubigadon-Durieux, C. (1911). J. Pharm. et Chimie, 2, 157.

Flury, F., and Neumann, W. (1935). Klin. Wschr., 16, 562.

Gold, H., Gelfand, B., and Hitzig, W. (1931). J. Pharm. Exper. Therap., 41, 89.

Krueger, E., and Unna, K. (1942). Ibid., 76, 282.

Leurier, J. (1889). J. Pharm. et Chimie, 2, 423.

Moe, G. K., and Visscher, M. B. (1938). J. Pharm. Exper. Therap., 64, 65.

Pieszcek, A. (1880). Arch. Pharmac., 252.

Planelles, K., and Werner, H. (1923). Arch. exp. Pathology and Pharm., 96, 21.

Robinson, G. C., and Wilson, F. N. (1918). J. Pharm. Exper. Therap., 10, 491.

Schmiedeberg, O. (1883). Arch. exp. Patho., 16, 149.

Shoppee, C. W. (1942). Ann. Rev. Biochem., 131.

Walther, R. (1940). Arch. exp. Path. Pharm., 195, 709 (quoted by Krueger and Unna).

Weese, H. (1936). Digitalis, G. Thieme, Leipsig.

Windaus, A., and Westphall, U. (1925). Nachr. Ges. Wissn. Goettingen, Math.-Phys., 78. 